\title{
Analysis of Genetic and Biogeography Diversity of Korean Indigenous Wild Rocambole (Allium monanthum Max)
}

\author{
Gihwan $\mathrm{Yi}^{1}$, Kyung-Min Kim ${ }^{2 *}$ \\ ${ }^{1}$ Division of Agroindustry \& Farm Management, Kyungpook National University, Daegu, South Korea; ${ }^{2}$ Division of Plant Biosci- \\ ences, School of Plant Biosciences, Kyungpook National University, Daegu, South Korea. \\ Email: gihwan@knu.ac.kr, ${ }^{*} k k m @ k n u . a c . k r$
}

Received March $4^{\text {th }}, 2013$; revised April 16 ${ }^{\text {th }}, 2013$; accepted May $10^{\text {th }}, 2013$

Copyright (C) 2013 Gihwan Yi, Kyung-Min Kim. This is an open access article distributed under the Creative Commons Attribution License, which permits unrestricted use, distribution, and reproduction in any medium, provided the original work is properly cited.

\begin{abstract}
This study was conducted to obtain baseline data describing Allium monanthum Max. for breeding an elite cultivar. A. monanthum has recently become popular vegetable in Korea owing to its unique flavors and nutraceutical effects. The agronomic traits of 271 accessions of A. monanthum collected throughout Korea were evaluated in this study. Leaf width showed the greatest variation $(0.1$ to $25 \mathrm{~mm})$ among traits evaluated, followed by leaf sheath length and number of cormlets. The average leaf sheath length and diameter, which are commonly used to evaluate quality in the market, were $1.29 \mathrm{~cm}$ and $0.3 \mathrm{~cm}$. Some superior accessions had a leaf sheath length of $>10 \mathrm{~cm}$ and diameter of $>1.1 \mathrm{~cm}$. The average weight of the cormlets ranged from 1 to $2 \mathrm{~g}$; however, one accession weighed more than $4 \mathrm{~g}$. The genetic diversity of $A$. monanthum calculated based on morphology and molecular distance was greater in Jeolla and Gyeoungsang provinces than Gyeonggi and Chungcheong provinces. Finally, seven elite accessions of $A$. monanthum were selected owing to their potential usefulness in future breeding projects.
\end{abstract}

Keywords: Allium monanthum; Indigenous; Agronomic Traits; Elite Lines; Breeding

\section{Introduction}

Allium monanthum (wild rocambole) is a wild relative of the chive and perennial monocotyledonous genera in Liliaceae. The bulb and white leaf sheath of $A$. monanthum has long been used as a food and for its antifungal activity and relaxant effects in Korean traditional therapy $[1,2]$. A. monanthum is widespread in the hills and plains of Korea and commonly used as culinary spice [3]. Although the growing areas of $A$. monanthum have increased in Korea, no commercial varieties have been released to date. Rather, farmers personally collect seeds or bulbils of $A$. monanthum from their natural habitat for the purpose of propagation and multiplication. This results in destruction of the natural habitat of the A. monanthum, as well as economic losses to farmers owing to mis-cultivation of A. grayi, which is similar in shape during vegetative periods. Even though $A$. monanthum and $A$. grayi belong to the same species, these plants differ in several aspects [4]. For example, A. monanthum is characterized by short plant height, oval leaf sheath and white or red flowers, while A. gray is taller (about $40 \mathrm{~cm}$ ), has

${ }^{*}$ Corresponding author. ovule to circular leaf sheathes with strong garlic flavors and white to pink flowers $[5,6]$.

In recent years, $A$. monanthum has been considered a health food, and there has been increasing demands for it owing to its various inorganic components, amino acids, polysaccharides and other active compounds such as glycosylglycerides [7,8]. Moreover, A. monanthum has become a high income crops relative to other winter crops due to its good adaptability to marginal land, tolerance of cold temperature, feasibility of cultivation, and short growth cycle (about 45 days), which enables it to be planted 3 to 4 times during winter in Korea [9]. Even though several studies have been conducted to analyze its chemical composition [10,11], growth habits and genetic diversity [4] and natural habitation according to altitude [12], limited information useful to future cultivation of $A$. monanthum such as sprouting habits, growing, and standard cultivations, are available. Accordingly, the present study was conducted to provide baseline data for selection of an elite A. monanthum germplasm. To accomplish this, major agronomic traits and genetic and biogeography diversity were investigated using 271 accessions of Korean indigenous A. monanthum collected nationwide 


\section{Materials and Methods}

\subsection{Plant Materials}

The plant materials used in this study were 271 accessions of indigenous $A$. monanthum germplasms collected from four provinces in Korea (Figure 1). All accessions were distributed by the National Gene Bank of the Rural Development Administration (RDA), Korea.

\subsection{Cultivation of $A$. monanthum}

Twenty bulbs of each accession were planted in an experimental field at Kyungpook National University with a distance of $80 \mathrm{~cm}$ between plants on March 1, 2012. Because there is no standard protocol for fertilization of A. monanthum, fertilizers were not applied. Irrigation was supplied by drip-watering when soils were heavily dry. Six plants representing each accession were planted in a row by randomized block design with three replications.

\subsection{Phenotypic Measurements}

The plant height, leaf width, number of tillers, diameter of leaf sheath, bulb weight, number of cormlets, and number of bulbils were measured and mean values of each trait were calculated from six plants of each line.

\subsection{Analysis of Genetic and Biogeographic Diversity}

Cluster analysis [13] of Korean indigenous accessions of A. monanthum using the Inter Simple Sequence Repeat (ISSR) marker based on morphology was employed in this experiment. ISSR analysis was counted by presence or absence of amplified DNA band using binary matrix equation. Cluster analysis of morphological markers was calculated by UPGMA (unweighted pair group method using arithmetic algorithm)-based cluster analysis and Euclidian distance. Dendrogram of A. monanthum collected from each region were constructed by TREECON program ver. 1.3b [14]. All data were rearranged and recalculated by collected site to analyze genetic and biogeographic diversity from the raw data presented by Lee et al. [13].

\section{Results}

\subsection{Variation of Agronomic Traits}

A. monanthum is emerging as health food in vegetable markets in Korea. However, there is no baseline information is available for breeding an elite cultivar of this plant. Therefore, major agronomic traits were evaluated using 271 accessions of Korean indigenous A. monanthum (Figure 2). All of the examined traits showed wide and similar continuous distribution patterns with a single peak. Among the traits investigated, plant height showed the most normal distribution, ranging from $75 \mathrm{~cm}$ to 10 $\mathrm{cm}$, while leaf sheaf length was the most skewed trait. The number of bulbils was evenly distributed. The coefficient of variance (CV) was highest for the width of leaves, which ranged from $25 \mathrm{~mm}$ to $0.1 \mathrm{~mm}$, followed by leaf sheath length and number of cormlets. There was narrow variation in emergence date with 5 days difference and a CV of 3.9 (Table 1).

\subsection{Genetic and Biogeographic Diversity}

As shown in Table 2, genetic diversity of 89 accessions of $A$. monanthum was evaluated based on cluster analysis of previous data [13]. A. monanthum accessions collected from the Gyeonggi and Chungcheong regions formed 2 and 1 clusters each based on morphology. Cluster analysis based on the ISSR marker showed a similar result in the Gyeonggi and Chungcheong region. Accessions collected from Jeolla and Gyeongsang formed 2 and 3 clusters each when investigated using morphological markers, but 8 and 9 clusters were identified using the ISSR marker, respectively (Figure 3).

\subsection{Selection of Useful Germplasm}

Potentially useful accessions for breeding an elite cultivar are listed in Table 3. GBA364 showed the longest leaf sheath $(3.7 \mathrm{~cm})$, while GBA219 showed the widest

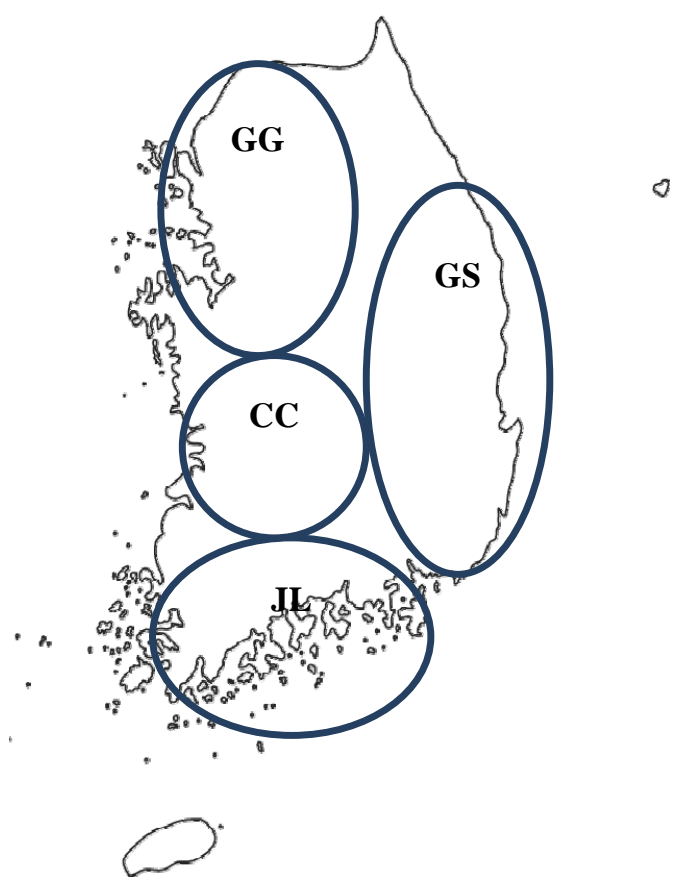

Figure 1. Collection sites of 271 Korean indigenous A. monanthum accessions grouped by region. GG: Gyeonggi Province, $\mathrm{CC}$ : Chungcheongnam and Chungcheongbuk provinces, GS: Gyeongsangnam and Gyeongsangbuk provinces, JN: Jeollanam and Jeollabuk provinces. 
leaf and a long leaf sheath. Leaf sheath length is an important trait used for evaluating the quality of A. monanthum in the market. Production of cormlets and bulbils was highest in accession GBA0245 and GBA0340, respectively. GBA0299 had short growth duration with good traits associated with cultivation. Finally, GBA 0289 showed the best overall performance when all agronomic traits were evaluated.
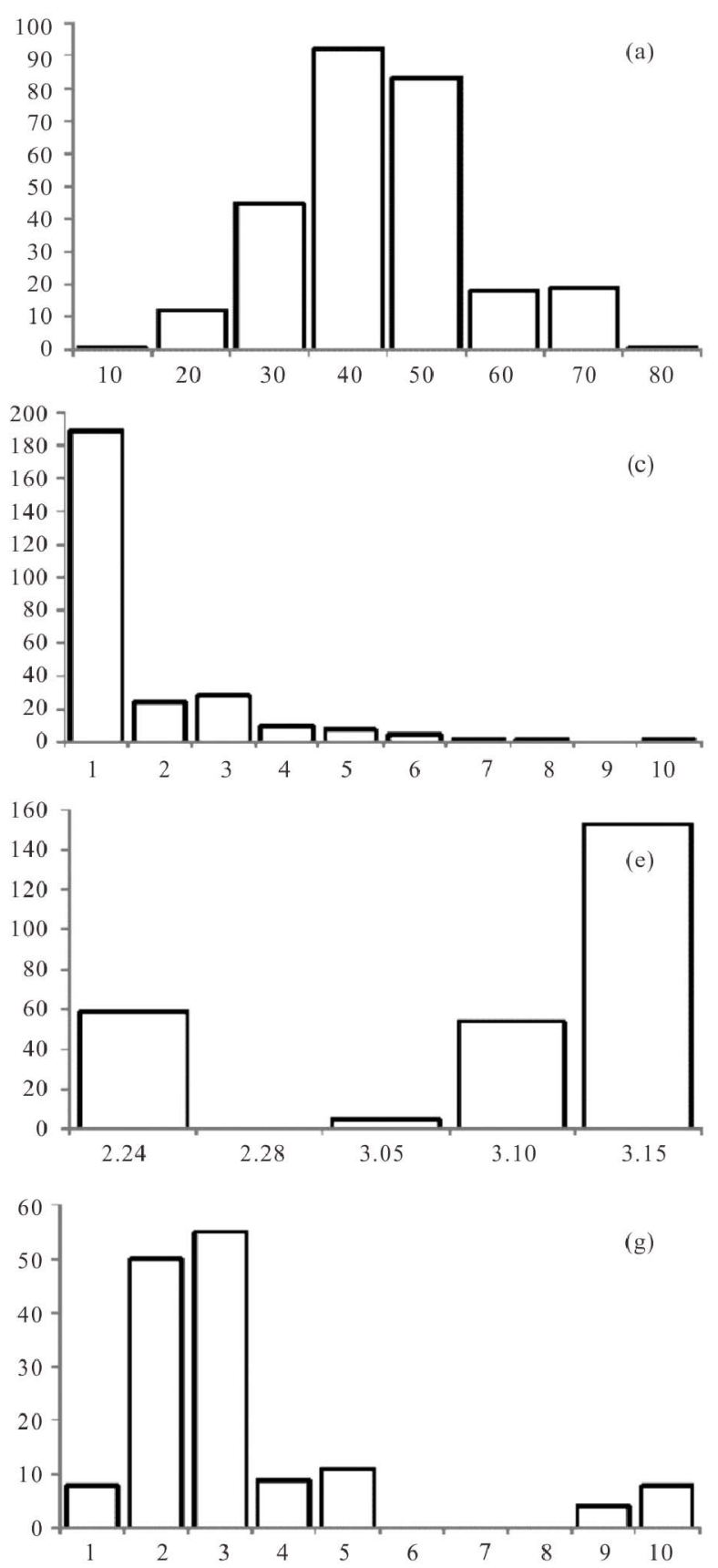

\section{Discussion}

Although market demand has recently increased, $A$. monanthum remains undomesticated in Korea. In the present study, potentially elite lines with large diversity were identified by screening agronomic traits among accessions of $A$. monanthum. Leaf sheath is animportant parameters influencing the marketability of A. monan-
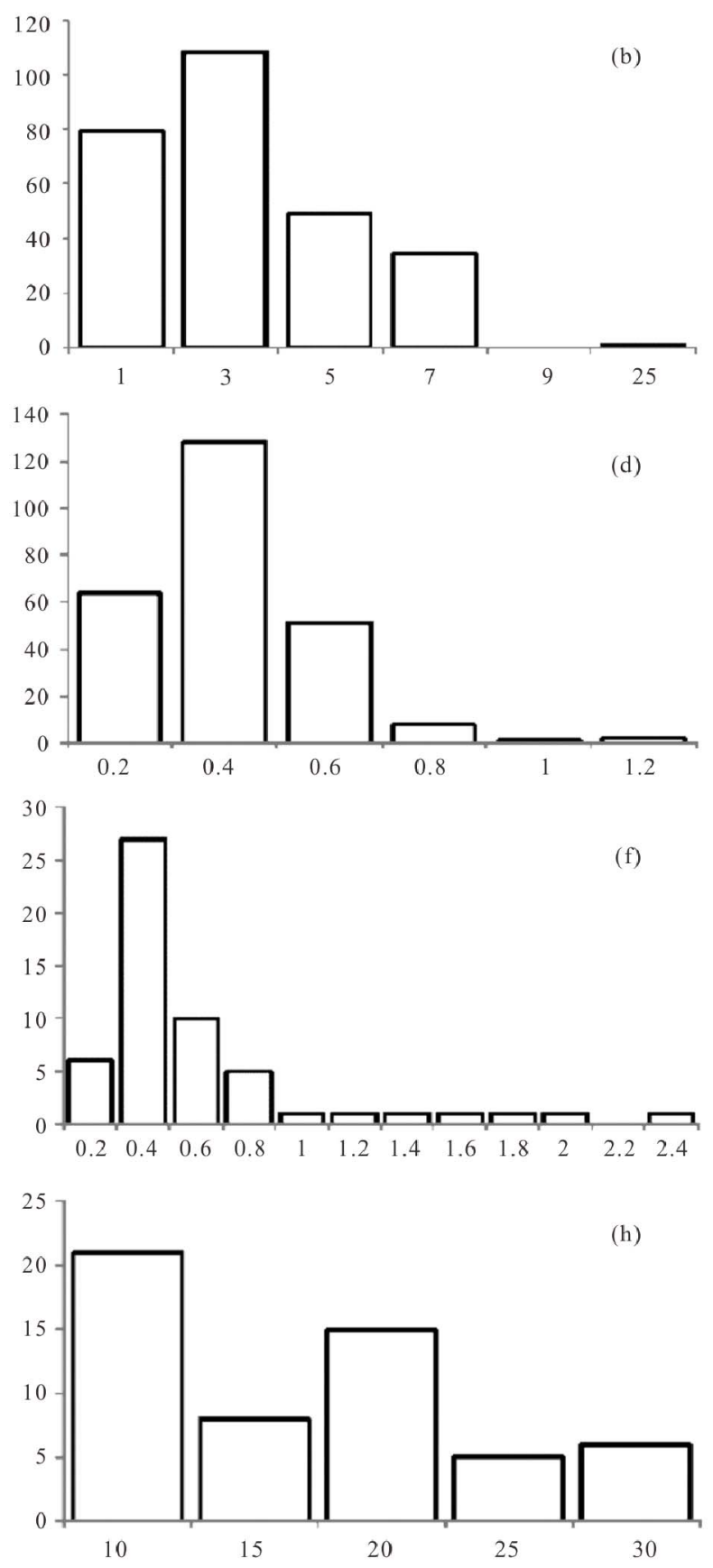

Figure 2. Distribution of major agronomic traits in 271 accessions of Allium monanthum. (a) Plant height (cm), (b) Leaf width (mm), (c) Length of leaf sheath (mm), (d) Diameter of leaf sheath (cm), (e) Date of emergence (MMDD), (f) Weight of bulbils (g), (g) Number of cormlets, (h) Number of bulbils. 


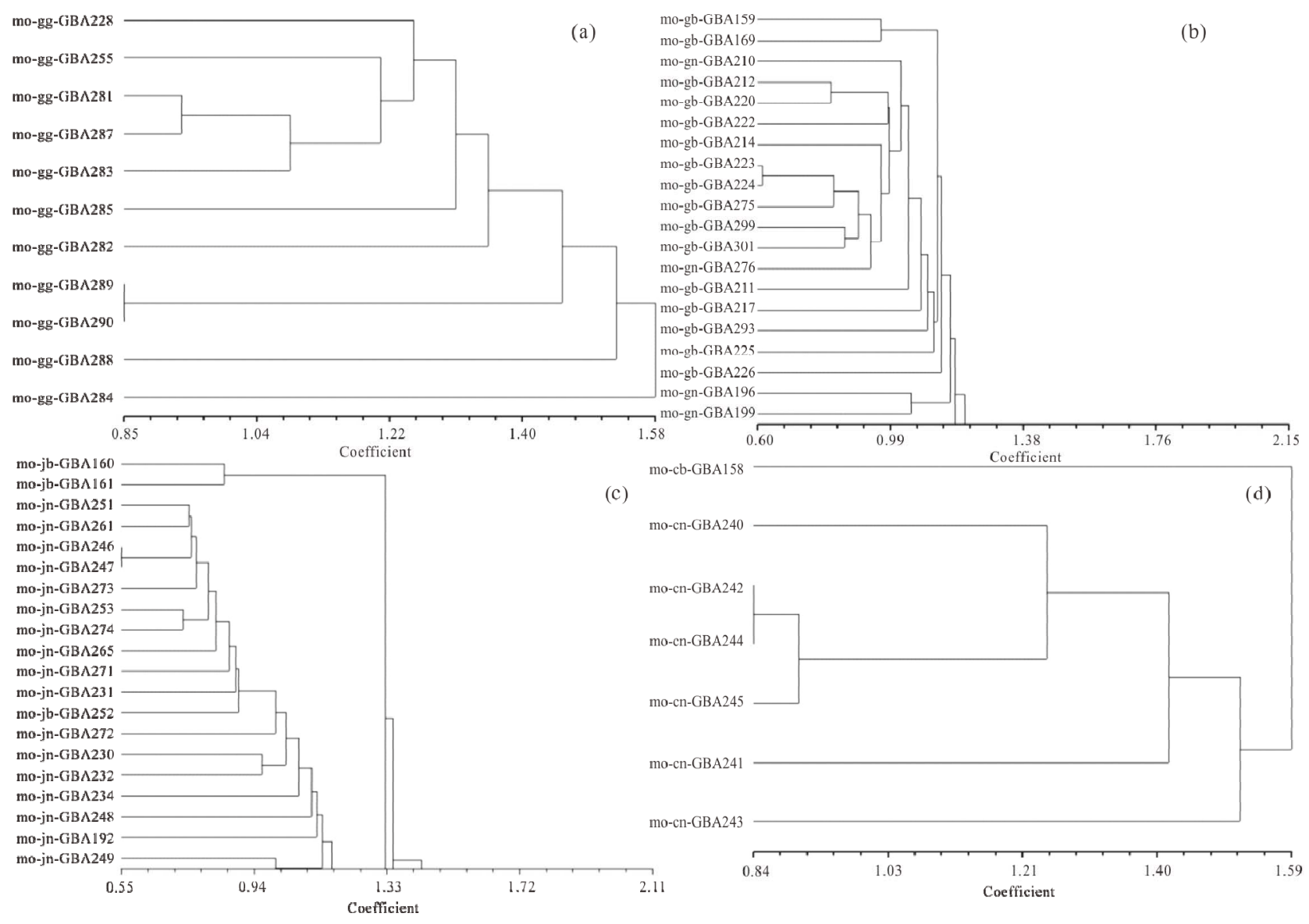

Figure 3. Genetic relationships among 89 accessions of $A$. monanthum using the TREECON program (ver.1.3b) based on ISSR markers. (a) Gyeonggi, (b) Gyeongsang, (c) Jeolla, D: Chungcheong.

Table 1. Analysis of agronomic traits of 271 indigenous Allium monanthum Max collected throughout Korea.

\begin{tabular}{lcccc}
\hline \multicolumn{1}{c}{ Trait } & No. of line & Mean $\pm \mathrm{SD}^{\mathrm{z}}$ & $\mathrm{CV}^{\mathrm{y}}$ & Range \\
\hline Plant height (cm) & 271 & $38.9 \pm 11.9$ & 30.5 & $74.71-9.8$ \\
Leaf width (mm) & 271 & $2.7 \pm 8.1$ & 303.4 & $25.0-0.1$ \\
Leaf sheath length (cm) & 271 & $1.29 \pm 1.67$ & 129.3 & $10.0-0.1$ \\
Leaf sheath diameter (cm) & 271 & $0.3 \pm 0.16$ & 49.7 & $1.1-0.1$ \\
bulb weight (g) & 271 & $1.13 \pm 0.9$ & 79.7 & $4.87-0.09$ \\
No. of cromlets & 145 & $3.1 \pm 3.3$ & 104.3 & $19.3-0.06$ \\
No. of bulbils & 55 & $1.1 \pm 1.0$ & 88.3 & $4.3-0.1$ \\
Emergence date & 271 & Mar. 8 \pm 5 day & 3.9 & Feb.24 - Mar.14 \\
\hline
\end{tabular}

${ }^{\mathrm{z}} \mathrm{SD}$ : standard deviation, ${ }^{\mathrm{y}} \mathrm{CV}$ : coefficient of variation.

Table 2. Cluster analysis of 89 accessions of A. monanthum based on morphology and polymorphism of ISSR markers.

\begin{tabular}{lccc}
\hline & \multirow{2}{*}{ Region } & \multicolumn{2}{c}{ No. of clusters classified by } \\
\cline { 3 - 5 } & & Morphology & ISSR marker $^{*}$ \\
\hline Gyeonggi & 11 & 10 & 119 \\
Chungcheong & 7 & 10 & 174 \\
Jeolla & 31 & 10 & 125 \\
Gyeongsang & 40 & 10 & 111 \\
Total & 89 & 10 & 529 \\
\hline
\end{tabular}

*No. of expressed band 
Table 3. List of elite germplasms selected from 271 lines of $A$. monanthum and their traits.

\begin{tabular}{|c|c|c|c|c|c|c|}
\hline Source & LW & LSL & LSD & NOC & NOB & DOE \\
\hline GBA0340 & 5.7 & 0.47 & 0.4 & 1.8 & 4.3 & Mar.11 \\
\hline GBA0289 & 5.3 & 0.33 & 0.5 & 4.2 & 0.3 & Mar.11 \\
\hline GBA0299 & 5.3 & 0.33 & 0.1 & 4.0 & - & Feb.24 \\
\hline GBA0364 & 5.0 & 3.7 & 0.6 & - & - & Mar.10 \\
\hline GBA0307 & 3.0 & 0.33 & 1.1 & 2.6 & - & Mar.11 \\
\hline GBA0245 & 4.7 & 0.43 & 0.3 & 19.3 & 2.3 & Mar.3 \\
\hline GBA0219 & 25.0 & 2.4 & $?$ & 2.6 & 1.9 & Mar.11 \\
\hline
\end{tabular}

LW: leaf width (mm), LSL: leaf sheath length (cm), LSD: leaf sheath diameter, NOC: number of cormlets, NOB: number of bulbils, DOE: date of emergence. Bold indicates extraordinary traits.

thum, with consumers preferring long and fleshy stalks. Some accessions were found to have extraordinary long $(10 \mathrm{~cm})$ and fleshy $(1.1 \mathrm{~cm}$ in diameter) leaf sheaths. These accessions can be used as a good resource for breeding a high quality $A$. monanthum. The bulb and leaf sheath is considered the edible part of $A$. monanthum due to its poor and slender leaves. However, accessions with wide leaves $(2.5 \mathrm{~cm})$ can be used as materials for developing a variety of edible leafy vegetables. Moreover, although the average weight of the bulb ranged from 1 to 2 $\mathrm{g}$, accessions with large bulbs ( $4 \mathrm{~g}$ ) were also identified. A. monanthum has been propagated by simple collection of naturally grown cormlets from fields. In the present study, we identified highly productive accessions that can be used for development of a variety for seed bulbs for propagation. Overall, seven elite lines of $A$. monanthum were selected from 271 accessions $A$. monanthum for use in future breeding programs.

The natural habitat of $A$. monanthum is affected by the degree of enclosure, intensity of light and altitude $[4,6]$. Cluster analysis by regions suggested that the genetic diversity of $A$. monanthum from central Korea was narrower than that from the southern and eastern regions. In terms of biogeographic diversity, the Jeolla and Gyeongsang regions were more diverse than the Chungcheong and Geonggi regions. These findings suggest that many varieties have disappeared as a result of urbanization and unfavorable surroundings, leaving only dominant species in those regions.

\section{Acknowledgements}

This research was supported by the Kyungpook National University Research Fund, 2012.

\section{REFERENCES}

[1] Shogakukan, "Encyclopedia of Chinese Drugs," Shanghai Science \& Technology Press, Tokyo, 1985, p. 226.
[2] J. K. Chang, "Wild Herbs for Health,” Nexus Co. Ltd. Seoul, 1996, p. 210.

[3] J. Y. Oh, M. G. Park, S. W. Kang, H. G. Park, S. J. Harn and S. M. Oh, "Polyploidy Distribution of Allium grayi in Korea,” Korean Journal of Horticultural Science, Vol. 37, No. 1, 1996, pp. 95-98.

[4] I. Riu, C. K. Kim, K. M. Kim and J. Y. Oh, "Growth Characteristics and Analysis of Phylogenetic Relationship of Allium monanthum and Allium grayi," Korean Journal of Horticultural Science \& Technology, Vol. 22, No. 3, 2004, pp. 270-277.

[5] T. B. Lee, “Colored Flora of Korea,” Hyangmunsa, 2006, pp. 701-707.

[6] K. M. Kim, S. K. Park, C. K. Kim and J. Y. Oh, "Characteristics of Natural Habits to Allium monanthum in South Korea," Korean Journal of Breeding Science, Vol. 42, No. 4, 2010, pp. 381-389.

[7] N. Beak, E. M. Ahn, H. Y. Kim, Y. D. Park, Y. J. Chang and S. Y. Kim, "Development of Biologically Active Compounds from Edible Plant Sources-IV. Isolation of Galactosyldiglyceride from Allium monanthum Max,” Korean Journal of Life Science, Vol. 11, No. 1, 2001, pp. 93-96.

[8] H. S. Choi, M. Y. Lee, Y. Jeong and G. M. Shin, "Hepatoprotective Effects of Allium monanthum Max. Extract on Ethanol Induced Liver Damage in Rat,” Preventive Nutrition and Food Science, Vol. 9, No. 3, 2004, pp. 245252. doi:10.3746/jfn.2004.9.3.245

[9] S. J. Hahn, "Effects of Keeping Warm Cultivation on the Growth and Yield of Allium grayi Regel," Korean Journal of Horticultural Science, Vol. 30, No. 1, 1989, pp. 1118.

[10] H. D. Chung, "Studies on the Contents of Chemical Constituents of Allium monanthum Max.," Youngnam Uniersity of the Life Science, Youngnam, 1974, pp. 345-351.

[11] H. D. Chung, M. S. Kim and J. S. Kim, "Studies on the Morphological Characteristics and Dormancy of Allium monanthum Max.," Youngnam University of the Life Science, Youngnam, 1975, pp. 363-370.

[12] K. M. Kim, C. K. Kim and J. Y. Oh, "Distribution Characteristics of the Four Species of Genus Allium at Differ- 
ent Altitudes in South Korea," Korean Journal of Agricultural and Forest Meteorology, Vol. 11, No. 4, 2009, pp. 252-255.

doi:10.5532/KJAFM.2009.11.4.252

[13] S. B. Lee, C. K. Kim, J. Y. Oh and K. M. Kim, “Classification of Allium monanthum and A. grayi by ISSR Mark- ers,” Korean Journal of Horticultural Science \& Technology, Vol. 29, No. 6, 2011, pp. 600-609.

[14] Y. Van de Peer and R. De Wachter, “TREECON: A Software Package for the Construction and Drawing of Evolutionary Trees," Computer Applications in the Biosciences, Vol. 9, No. 2, 1993, pp. 177-182. 